\title{
Pathobiology, irradiation dosimetric parameters and therapy of radiation-induced gastric damage: a narrative review
}

\author{
Michael J. McKay ${ }^{1,2,3}$, Richard Foster ${ }^{1}$ \\ ${ }^{1}$ Northern Cancer Service, North West Cancer Centre, Burnie, Tasmania, Australia; ${ }^{2}$ Rural Clinical School, The University of Tasmania, Northwest \\ Regional Hospital, Burnie, Tasmania, Australia; ${ }^{3}$ Olivia Newton John Cancer Research Institute, Heidelberg, Victoria, Australia \\ Contributions: (I) Conception and design: Both authors; (II) Administrative support: None; (III) Provision of study materials or patients: Both authors; \\ (IV) Collection and assembly of data: Both authors; (V) Data analysis and interpretation: Both authors; (VI) Manuscript writing: Both authors; (VII) \\ Final approval of manuscript: Both authors. \\ Correspondence to: Prof. Michael J. McKay, MD, PhD. Northern Cancer Service, North West Cancer Centre, Burnie, Tasmania 7320, Australia. \\ Email: michael.mckay@ths.tas.gov.au.
}

Objective: To review the pathobiology, irradiation dosimetric parameters and other risk factors, and therapy of radiation-induced gastric damage (RIGD).

Background: RIGD is a side-effect of upper abdominal radiotherapy. Acute toxicities are usually mild and self-limiting. Late toxicities are potentially life-threatening and include bleeding, perforation or stenosis. The data on RIGD is mainly historical and derived from neoplasms and treatments where the role of radiotherapy is contracting, such as para-aortic nodal irradiation for testis and cervical cancer and Hodgkin's Disease. On the other hand, the role of radiotherapy is expanding, especially with stereotactic body radiotherapy (SBRT) treatments evolving for both primary and secondary upper gastrointestinal neoplasms, which might be expected to increase the frequency of RIGD. Pathoclinical and radiation dosimetric data which might predict the risk of RIGD are evaluated.

Methods: English language articles between 1945 and December 2020, using PubMed and Embase, searching titles for keywords including: radiation; ionizing; radiotherapy; gastritis and 65 articles were selected for review. There may have been a risk of bias in the studies evaluated, since the majority of reports were retrospective, largely descriptive and qualitative.

Conclusions: A common pathoclinical theme in RIGD is inflammation. Numerous factors predict for a greater likelihood of RIGD, including radiation fraction size and dose, concurrent chemotherapy and previous abdominal surgery. Therapy is pathology-dependent and comprises pharmacological, interventional and in the most severe cases, surgical approaches. It is timely to review the topic of RIGD, discuss the limitations of the data and highlight the need for future research directions.

Keywords: Radiation; radiotherapy; gastritis; gastric; damage

Submitted Jun 24, 2021. Accepted for publication Oct 25, 2021.

doi: 10.21037/jgo-21-361

View this article at: https://dx.doi.org/10.21037/jgo-21-361

\section{Introduction}

Radiation-induced gastric damage (RIGD) is a common side-effect of upper abdominal radiotherapy. Most cases are mild and self-limiting, occurring during or within the first couple of months after radiotherapy treatments (acute toxicities). Most cases comprise acute gastritis.
Late toxicities, defined as occurring three months or later after the completion of radiation therapy (RT) (1), can be potentially life-threatening. Symptomatic RIGD requiring endoscopic/histological evaluation affects fewer than $1 \%$ of patients receiving upper abdominal radiotherapy. Endoscopic and histological changes depend on timing in relation to irradiation, but typically include signs of either 
Table 1 Symptoms and signs of RIGD

\begin{tabular}{lll}
\hline Presentation & Symptoms & Signs \\
\hline Acute $<3$ months & $\begin{array}{l}\text { Anorexia; nausea; vomiting; dyspepsia; } \\
\text { epigastric discomfort or pain; haematemesis; melaena }\end{array}$ & $\begin{array}{l}\text { Epigastric tenderness; pallor; haemodynamic } \\
\text { compromise/shock }\end{array}$ \\
Delayed/late >3 months & $\begin{array}{l}\text { Anorexia; chronic dyspepsia; epigastric discomfort } \\
\text { or pain; haematemesis; melaena }\end{array}$ & $\begin{array}{l}\text { Epigastric tenderness; pallor; haemodynamic; } \\
\text { compromise/shock }\end{array}$ \\
\hline
\end{tabular}

RIGD, radiation-induced gastric damage.

acute or chronic inflammation. Symptoms are nonspecific and often mild with acute reactions (such as dyspepsia, anorexia, nausea or epigastric discomfort). Late reactions may be (atrophic) gastritis, an ulcer or its complications (bleeding, stenosis, perforation, penetration or fistula), or significant gastrointestinal (GI) bleeding (Table 1). As they are almost always the most severe, this review addresses mainly late gastric side-effects of upper abdominal irradiation.

Despite its importance, there are relatively little data on RIGD. RIGD historically related to paraaortic irradiation for Hodgkin's Lymphoma, testis and cervix cancer (see below); it now occurs most commonly in the context of neoadjuvant or adjuvant radiotherapy for stomach cancer, or can be a co-morbidity of irradiation of adjacent organs, such as the oesophagus, pancreas or liver. Potentially, RIGD incidence will increase, with an expanding role for stereotactic treatments for metastases, pancreatic and liver tumours.

Broadly speaking, the irradiation tolerance of the stomach is intermediate between that of other parts of the gastrointestinal tract (e.g., small intestine and rectum). Radiation doses between 45-50 Gy to the entire organ rarely cause significant RIGD (see below).

Treatment of RIGD depends on its nature and chronicity. It ranges from simple dietary/supportive measures to endoscopic treatments, or surgery for more serious pathologies. Although modern conformal radiotherapeutic techniques may reduce the incidence and severity of RIGD, some more contemporaneous techniques such as stereotactic body radiotherapy (SBRT) have been implicated in causing RIGD (2).

This review is timely for the following reasons, including the high clinical relevance and paucity of data on the topic, the fact that RIGD may interfere with a patient being able to tolerate a full course of upper abdominal radiotherapy, with consequently impaired clinical outcomes and also, the fact that there is an expanding role for SBRT to upper abdominal organs/tissues/tumours (e.g., pancreas, liver, adrenals, other metastases) where RIGD is increasingly possible.

We present the following article in accordance with the
Narrative Review reporting checklist (available at https:// dx.doi.org/10.21037/jgo-21-361).

\section{Anatomy and physiology}

The stomach is a capacious tubular organ (volume up to $2 \mathrm{~L}$ in adults) situated in a subdiaphragmatic position. Its inlet is the gastroesophageal junction and outlet is the gastroduodenal junction. It is comprised of four layers (mucosa, submucosa, muscular coat and serosa). The muscular coat has three layers of muscle: transverse, longitudinal and oblique. The stomach is divided into a number of regions; different stomach regions subserve a variety of functions (Figure 1) (3).

\section{Preclinical and investigational studies of RIGD}

A descriptive/histomorphologic study of the effect of high dose irradiation on the stomach of mammals was performed by Breiter et al. [1989] (4). They developed a rat model of both acute and late radiation effects on the stomach. The region of the upper abdomen corresponding to the stomach of the animals was treated with single doses of radiation (14-28.5 Gy, in groups). Acute deaths were characterised by erosive/ulcerative gastritis, whereas late mortality cases showed variable pathologies, including stomach dilatation and gastroparesis, associated with replacement of the columnar gastric epithelium by multilayered squamous columnar epithelium. Late gastric obstruction was also encountered, followed later in surviving animals by epithelial atrophy and intestinal metaplasia. The different pathological states occurred in different temporal stages. The morphological changes mirrored those previously reported from a number of animal model studies [(5) and references therein]. However, it is unknown how representative of the clinical situation with conventional multifraction radiotherapy these animal studies are, although they may be informative as regards the high fractional doses used in modern stereotactic radiotherapy. 


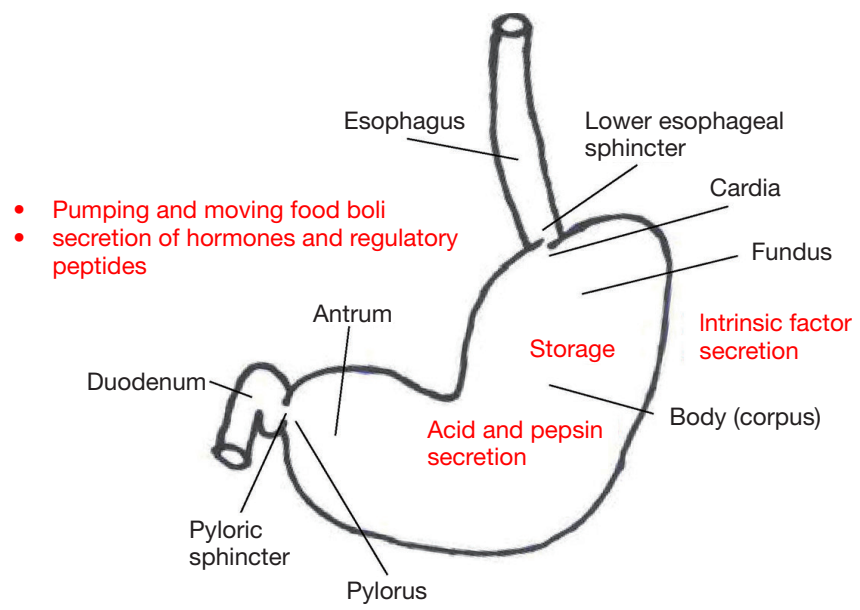

Figure 1 Summary overview of stomach structure and function. Each gastric (and esophageal) region is indicated with a line, whereas the various gastric functions are demarcated in red. Both the fundus and body have storage functions, whereas the body is responsible for hydrochloric acid and pepsin secretion by chief cells. Intrinsic factor, required for vitamin B12 (cobalamin) absorption in the terminal ileum, is secreted by the parietal cells in the fundus and body of the stomach. The antrum and pylorus have both mechanical (pumping action and food bolus movement) and secretory functions; for example, they are responsible for gastrin release, which in turn simulates gastric acid and peptide production and gastric peristalsis (3).

Stomach stem cell responses after irradiation have also been studied (6). These authors found that stomach clonogenic (stem) cells had an excellent capacity to repair sublethal radiation damage and recovered after irradiation with a relatively fast doubling time of 43 hours. They suggested that efficient repair of radiation damage in stomach-derived adenocarcinomas may contribute to their radioresistance.

Goldgraber et al. [1954] (7) performed a study of serial endoscopic biopsies of the gastric fundus after irradiation in three patients. There was considerable variation between patients in time of onset, reaction severity, and reaction duration. They described characteristic initial degenerative, followed by inflammatory mucosal and submucosal changes and disorganised architectural gastric mucosal appearances. Initial damage was manifest in the depths of the fundic glands, affecting both chief and parietal cells. Changes were patchy within individual cases, affecting accuracy of biopsies for different reaction stages.

\section{Clinical effects of irradiation on the stomach}

Many studies of gastrointestinal damage from radiation, group multiple sites within the analysis. For example, stomach/duodenum or stomach/small intestine, or even 'upper gastrointestinal tract'. This can cloud the specific effect of the radiation intervention on the stomach specifically, although a number of studies (see below) do address stomach-specific morbidity.

Symptoms and signs of RIGD are pathology-dependent. RIGD can be classified as acute or chronic (Table 1). Such damage, or 'effects', are operationally defined as occurring up to, or later than, 3 months from the start of radiotherapy (1). So-called consequential late effects, where a typically severe, acute effect becomes persistent, occur infrequently in the gastrointestinal tract. Mild acute effects secondary to RIGD are by far the most common, affecting up to around half of all patients receiving upper abdominal or stomach radiotherapy (8). They are usually self-limiting, resolve within days to weeks of the end of the course of irradiation, and typically respond to symptomatic measures. However, late effects are potentially more serious, the most common RIGD lesion being ulceration, a current grading of which is shown in Table 2. Ulceration can have secondary consequences such as bleeding, penetration, perforation, fistula formation and progressive gastric wall fibrosis, not infrequently leading to gastric outlet obstruction. Gastric outlet obstruction is also a complication of ulcer formation in the pyloric region. Gastric perforation is usually secondary to ulcer formation, but occurs infrequently in the absence of ulcers. The exception is where the stomach wall is involved with tumour; classically, perforations in this setting occur with gastric non-Hodgkin's 
Table 2 Common Toxicity Criteria for Adverse Events (CTCAE) v5 (Nov 2017) grading for gastric haemorrhage and gastric ulcer

\begin{tabular}{|c|c|c|}
\hline Grade & Gastric haemorrhage & Gastric ulcer \\
\hline Grade 2 & Moderate symptoms; intervention indicated & $\begin{array}{l}\text { Symptomatic; altered GI function; medical intervention indicated; } \\
\text { limiting instrumental ADLs }\end{array}$ \\
\hline Grade 3 & $\begin{array}{l}\text { Therapy indicated; invasive intervention indicated; } \\
\text { hospitalisation }\end{array}$ & $\begin{array}{l}\text { Severely altered GI function; tube feeding or hospitalisation; } \\
\text { elective operative intervention indicated }\end{array}$ \\
\hline Grade 4 & $\begin{array}{l}\text { Life-threatening consequences; urgent intervention } \\
\text { indicated }\end{array}$ & $\begin{array}{l}\text { Life-threatening consequences; urgent operative intervention } \\
\text { indicated }\end{array}$ \\
\hline Grade 5 & Death by adverse event & Death by adverse event \\
\hline
\end{tabular}

RIGD, radiation-induced gastric damage; ADLs, activities of daily living.

Table 3 Predisposing factors to RIGD

Patient factors
Older age
Smoking
Vasculopathy and predisposing conditions (hypertension,
diabetes, IHD, other vascular disease)
Previous abdominal surgery
Genetic radiosensitivity syndromes (e.g., AT, NBS, fanconi
anaemia)
Treatment factors
Concurrent chemotherapy or TKIs
Radiation fractionation
Radiation volume
Cumulative dose
Conventional or precision radiotherapy

Tumour factors

Larger tumours

Radioresistant tumours

RIGD, radiation-induced gastric damage; IHD, ischaemic heart disease; AT, ataxia telangiectasia; NBS, Nijmegen breakage syndrome; TKIs, tyrosine kinase inhibitors.

lymphoma (9). Overall, severe late effects have been estimated to occur in roughly $0.5-3 \%$ of patients receiving gastrointestinal tract radical radiotherapy (10).

\section{Susceptibility to RIGD}

A number of factors can predispose an individual receiving radiotherapy to the upper GI, to RIGD. These can be broadly considered as patient-related, treatment-related and tumour-related factors (Table 3). Patient-related factors are largely common co-morbidities causing vascular disease. They can influence both the risk of initial RIGD presentation, as well as its progression. Rare, recessivelytransmitted, cancer-prone genetic radiosensitivity disorders such as Ataxia telangiectasia (OMIM \#208900) (11) and Nijmegen Breakage Syndrome (OMIM \#251260) (12), lead to radiosensitivity in all irradiated tissues $(13,14)$.

Multiple treatment-related factors (in addition to irradiation-dealt with in the following section) impact RIGD risk. The most common are chemotherapeutic agents, for example, as used in stomach adenocarcinoma chemoradiotherapy, such as ECF (epirubicin, cyclophosphamide and 5-flourouracil) $(15,16)$. Interestingly, one frequently used agent in GI cancers, 5-flourouracil, does not seem to increase late stomach morbidity when used in conjunction with irradiation, at least to doses of radiation up to 45-50 Gy $(17,18)$, although most chemotherapeutic agents can exacerbate acute RIGD.

Prior surgery increases RIGD risk. The EORTC H2 and $\mathrm{H} 5$ trials in Hodgkin Disease examined patients randomly assigned to staging laparotomy or not. They found that gastric late effects were statistically greater $(11.5 \%$ vs. $2.7 \%)$ in those who had had an exploratory laparotomy plus paraaortic irradiation, versus those who had paraaortic irradiation but had not had prior abdominal surgery (19).

Tumour factors such as size and radioresistant histology can also affect RIGD risk as a dependent variable. Larger tumours require larger treatment volumes; tumours of a radioresistant histology may be subject to higher radiation doses. 


\section{Radiation tolerance of the stomach: clinical studies and dosimetric parameters}

Emami et al. [1991] (20) estimated the stomach's radiation tolerance, with endpoints of ulceration and perforation: TD $5 / 5$ (the probability of $5 \%$ complications within 5 years of treatment) of $50 \mathrm{~Gy}$ and TD 50/5 of $65 \mathrm{~Gy}$, both when the entire organ is irradiated (20). When smaller stomach volumes are treated, organ tolerance is greater (TD 5/5 up to $60 \mathrm{~Gy}$ when one-third of the organ is irradiated).

There are a number of radiation-associated RIGD risk factors (Table 3). Radiotherapy fraction size was critical in the $\mathrm{H} 2$ and H5 Hodgkin Disease EORTC randomised trials. Patients received substantial concomitant stomach doses as part of paraaortic irradiation with an anteroposterior parallel opposed pair, receiving one of three different weekly fractionation schedules: $5 \times 2 \mathrm{~Gy}$, $4 \times 2.5$ Gy or $3 \times 3.3$ Gy; the relative frequency of serious radiation-induced gastric late effects, were $4 \%, 9 \%$ and $22 \%$, respectively (19). There was a multiplicative effect of fraction size and prior abdominal surgery: those who received the $3.3 \mathrm{~Gy} /$ fraction regime and who also had an exploratory staging laparotomy, had a $39 \%$ serious complication rate. Likewise, studies of paraaortic irradiation for stage I testicular teratoma also showed a significant rate of RIGD (ulceration) (5\% of 146 mainly young male patients) (21). Pre-existing peptic ulcer disease increased the rate of ulcer formation. Similar results were seen for testicular seminoma (22).

A large series of testicular cancer cases receiving paraaortic irradiation was reported from the US Walter Reed Army Medical Center [see (17) and refs therein]. Upper GI symptoms started to occur with doses of 40 to $50 \mathrm{~Gy}$; gastric ulcers occurred in $15 \%$ of cases exposed to over 50 Gy of paraaortic irradiation, and $<4 \%$ of those receiving $<50 \mathrm{~Gy}$. None occurred in cases receiving $<45$ Gy.

The RIGD risk, both for acute and late effects, is proportional to the volume irradiated, at least for chemoradiation. For example, Murphy et al. [2007] (23) treated locally advanced pancreatic cancers with radiation (36 Gy in 15 fractions) and concurrent gemcitabine $\left(1,000 \mathrm{mg} / \mathrm{m}^{2} \times 3\right)$. They found a frequency of upper GI bleeding of $8 \%$; patients with larger planning treatment volumes (PTVs) were at highest risk of severe acute and late complications (23).

A series of 121 cervix cancer cases were treated at the MD Anderson Hospital with 50 Gy paraaortic irradiation. In $8.3 \%$ there were radiological abnormalities of the distal stomach, with 10 cases of gastric ulcer, developing between 1 and 25 months after the completion of radiotherapy (24).

SBRT is increasingly used for localised pancreatic and hepatic tumours. In one study, 22 pancreatic cancer patients were treated with $3 \times 15$ Gy fractions of SBRT; 4 experienced severe gastritis or ulceration of the stomach or duodenum and one affected patient had a stomach perforation (25). Key stomach irradiation constraints (dosing parameters) have now been suggested; they include that $<4 \%$ of the stomach can receive $>22.5$ Gy; the maximum point dose should be $<30$ Gy for 3 -fraction SBRT; and the 50\% isodose should not span the diameter of the stomach $(18,26)$. Likewise, stomach is an organ at risk after liver tumour SBRT $(2,27,28)$.

\section{Preventive strategies}

Proton pump inhibitors will reduce gastric acid formation, a key contributing factor to subsequent ulcer formation. Meticulous irradiation technique, with close attention to gastric tolerances, should reduce RIGD frequency. Fractionation is important (see above), so adherence to around 2 Gy per fraction, where possible, is recommended. For stomach cancer irradiation, reducing gastric distension by fasting/ingestion of small amounts of clear fluids, in the two hours before radiotherapy simulation and treatment, will provide the smallest possible target volume. Modern radiotherapy approaches such as intensity modulated radiotherapy/volumetric arc radiotherapy (IMRT/ VMAT) may diminish RIGD risk by minimising organ at risk irradiation. Motion management techniques such as respiratory gating may assist.

\section{Therapy}

Various therapies for RIGD have been described (Table 4) (29). These are tailored to the pathoclinical type of RIGD and can be considered in three classes: pharmacological therapies, physical interventional therapies and surgery. Key pharmacological interventions to reduce stomach acid production, which may exacerbate other acute and late effects, are proton pump inhibitors. A more specific drug that has been successfully used to mitigate intractable bleeding from radiation-induced gastritis is growth hormone (30). Of the physical/endoscopic/interventional approaches to RIGD, endoscopic argon laser coagulation has often been used for diffuse superficial telangiectasia, because of its minimal penetration into tissue; multiple case 
Table 4 Therapies used in the treatment of RIGD

\begin{tabular}{llll}
\hline Presentation & Pharmacological & Interventional & Surgical \\
\hline Acute gastritis & Proton pump inhibitors & Argon plasma laser ablation & Rarely required \\
Acute gastric ulcers & Proton pump inhibitors & $\begin{array}{l}\text { Endoscopic intervention; } \\
\text { embolization for severe bleeding }\end{array}$ & Partial gastrectomy \\
Ulcers, strictures or fistulas & Proton pump inhibitors & $\begin{array}{l}\text { Stricture dilatation; hyperbaric } \\
\text { oxygen }\end{array}$ & $\begin{array}{l}\text { Partial gastrectomy; extensive surgery for } \\
\text { fistulas }\end{array}$ \\
\hline
\end{tabular}

RIGD, radiation-induced gastric damage.

reports attest to the hemostatic success of the technique, either alone or in conjunction with radiofrequency ablation $(31,32)$. Hyperbaric oxygen (33), has also successfully been employed. Arterial embolization has been usefully used in cases of RIGD (hemorrhagic gastritis) (34). On occasion, pyloric sphincter dilatation may be successful for stricture. Surgery is largely reserved for the more serious RG complications such as gastric outlet obstruction, perforation or intractable bleeding (either secondary to chronic ulceration or haemorrhagic gastritis) (35). Normally, partial gastrectomy can be performed. Dumping may complicate surgery and vitamin B12 supplementation can be needed. More extensive surgery may be required for the less common proximal stomach RIGD, or for fistula formation.

\section{Summary, conclusions and future directions}

RIGD is common. The acute phase is usually mild and selflimiting and can be controlled by drugs without needing investigation unless symptoms are severe or not responding to conservative measures. Late manifestations may be mild—atrophic gastritis or B12 malabsorption-but there can be severe consequences. A common pathoclinical theme is that of inflammation. Numerous factors predict for a greater likelihood of RIGD, in particular radiation fraction size and dose, concurrent chemotherapy and previous abdominal surgery. Therapy is pathology-dependent and comprises pharmacological, interventional and in the most severe cases, surgical approaches.

The true incidence of RIGD is unknown, since available studies are generally retrospective, largely descriptive and qualitative in nature. RIGD data could be prospectively collected within departments for use in a patterns of care study, analogous to those previously performed in the USA (36). Accurate volumetric data recorded could help with analysis of radiation dose, volume and time factors and matching with Medicare data (in Australia) or insurance data in the USA could give new insights into the incidence and severity of RIGD.

There is also no systematic approach to the management of RIGD, partly due to its heterogeneity in pathoclinical characteristics. No guidelines as of yet exist for the management of RIGD; hence treatment needs to be individualised. One limitation of the field is the lack of quantitative data on the association between RIGD incidence and factors such as radiation dose-volume-time relationships, especially for stereotactic radiotherapy; these should accrue with increasing experience with modern radiotherapy techniques.

\section{Acknowledgments}

The authors thank Dr. Kim Taubman for thoughtful comments on the manuscript.

Funding: None.

\section{Footnote}

Reporting Checklist: The authors have completed the Narrative Review reporting checklist. Available at https:// dx.doi.org/10.21037/jgo-21-361

Conflicts of Interest: Both authors have completed the ICMJE uniform disclosure form (available at https://dx.doi. org/10.21037/jgo-21-361). The authors have no conflicts of interest to declare.

Ethical Statement: The authors are accountable for all aspects of the work in ensuring that questions related to the accuracy or integrity of any part of the work are appropriately investigated and resolved.

Open Access Statement: This is an Open Access article distributed in accordance with the Creative Commons 
Attribution-NonCommercial-NoDerivs 4.0 International License (CC BY-NC-ND 4.0), which permits the noncommercial replication and distribution of the article with the strict proviso that no changes or edits are made and the original work is properly cited (including links to both the formal publication through the relevant DOI and the license). See: https://creativecommons.org/licenses/by-nc-nd/4.0/.

\section{References}

1. Czito BG, Meyer JJ, Willett CG. Overview of gastrointestinal toxicity of radiation therapy. UpToDate (last updated Apr 13, 2020).

2. Minn AY, Koong AC, Chang DT. Stereotactic body radiation therapy for gastrointestinal malignancies. Front Radiat Ther Oncol 2011;43:412-27.

3. Hunt RH, Camilleri M, Crowe SE, et al. The stomach in health and disease. Gut 2015;64:1650-68.

4. Breiter N, Trott KR, Sassy T. Effect of X-irradiation on the stomach of the rat. Int J Radiat Oncol Biol Phys 1989;17:779-84

5. Friedman N. Effects of radiation on the gastrointestinal tract, including the salivary glands, the liver and the pancreas. Arch Pathol 1942;34:749-85.

6. Chen KY, Withers HR. Survival characteristics of stem cells of gastric mucosa in $\mathrm{C} 3 \mathrm{H}$ mice subjected to localized gamma irradiation. Int J Radiat Biol Relat Stud Phys Chem Med 1972;21:521-34.

7. Goldgraber MB, Rubin CE, Palmer WL, et al. The early gastric response to irradiation; a serial biopsy study. Gastroenterology 1954;27:1-20.

8. Shadad AK, Sullivan FJ, Martin JD, et al. Gastrointestinal radiation injury: symptoms, risk factors and mechanisms. World J Gastroenterol 2013;19:185-98.

9. de Jong D, Aleman BM, Taal BG, et al. Controversies and consensus in the diagnosis, work-up and treatment of gastric lymphoma: an international survey. Ann Oncol 1999;10:275-80.

10. Andreyev J. Gastrointestinal symptoms after pelvic radiotherapy: a new understanding to improve management of symptomatic patients. Lancet Oncol 2007;8:1007-17.

11. Available online: https://www.omim.org/entry/208900

12. Available online: https://www.omim.org/entry/251260

13. Leong T, Borg M, McKay M. Clinical and cellular radiosensitivity in inherited human syndromes. Clin Oncol (R Coll Radiol) 2004;16:206-9.

14. Amirifar P, Ranjouri MR, Lavin M, et al. Ataxia- telangiectasia: epidemiology, pathogenesis, clinical phenotype, diagnosis, prognosis and management. Expert Rev Clin Immunol 2020;16:859-71.

15. Ilson DH. Advances in the treatment of gastric cancer. Curr Opin Gastroenterol 2017;33:473-6.

16. Leong T, Smithers BM, Haustermans K, et al. TOPGEAR: A Randomized, Phase III Trial of Perioperative ECF Chemotherapy with or Without Preoperative Chemoradiation for Resectable Gastric Cancer: Interim Results from an International, Intergroup Trial of the AGITG, TROG, EORTC and CCTG. Ann Surg Oncol 2017;24:2252-8.

17. Coia LR, Myerson RJ, Tepper JE. Late effects of radiation therapy on the gastrointestinal tract. Int J Radiat Oncol Biol Phys 1995;31:1213-36.

18. Kavanagh BD, Pan CC, Dawson LA, et al. Radiation dosevolume effects in the stomach and small bowel. Int J Radiat Oncol Biol Phys 2010;76:S101-7.

19. Cosset JM, Henry-Amar M, Burgers JM, et al. Late radiation injuries of the gastrointestinal tract in the $\mathrm{H} 2$ and H5 EORTC Hodgkin's disease trials: emphasis on the role of exploratory laparotomy and fractionation. Radiother Oncol 1988;13:61-8.

20. Emami B, Lyman J, Brown A, et al. Tolerance of normal tissue to therapeutic irradiation. Int J Radiat Oncol Biol Phys 1991;21:109-22.

21. Hamilton CR, Horwich A, Bliss JM, et al. Gastrointestinal morbidity of adjuvant radiotherapy in stage I malignant teratoma of the testis. Radiother Oncol 1987;10:85-90.

22. Vallis KA, Howard GC, Duncan W, et al. Radiotherapy for stages I and II testicular seminoma: results and morbidity in 238 patients. Br J Radiol 1995;68:400-5.

23. Murphy JD, Adusumilli S, Griffith KA, et al. Full-dose gemcitabine and concurrent radiotherapy for unresectable pancreatic cancer. Int J Radiat Oncol Biol Phys 2007;68:801-8.

24. Goldstein HM, Rogers LF, Fletcher GH, et al. Radiological manifestations of radiation-induced injury to the normal upper gastrointestinal tract. Radiology 1975;117:135-40.

25. Høyer M. Re-irradiation with stereotactic body radiation therapy (SBRT). Chin Clin Oncol 2017;6:S15.

26. Chang DT, Schellenberg D, Shen J, et al. Stereotactic radiotherapy for unresectable adenocarcinoma of the pancreas. Cancer 2009;115:665-72.

27. Gkika E, Strouthos I, Kirste S, et al. Repeated SBRT for in- and out-of-field recurrences in the liver. Strahlenther Onkol 2019;195:246-53. 
28. Bujold A, Massey CA, Kim JJ, et al. Sequential phase I and II trials of stereotactic body radiotherapy for locally advanced hepatocellular carcinoma. J Clin Oncol 2013;31:1631-9.

29. Shadad AK, Sullivan FJ, Martin JD, et al. Gastrointestinal radiation injury: prevention and treatment. World J Gastroenterol 2013;19:199-208.

30. Zhang L, Xia WJ, Zhang ZS, et al. Growth hormone used to control intractable bleeding caused by radiation-induced gastritis. World J Gastroenterol 2015;21:9453-6.

31. Ross A, Kuppusamy M, Low D. Endoscopic management of postesophagectomy hemorrhagic radiation gastritis with radiofrequency ablation and argon plasma coagulation. Gastrointest Endosc 2012;75:1285-6.

32. Wada S, Tamada K, Tomiyama T, et al. Endoscopic hemostasis for radiation-induced gastritis using argon plasma coagulation. J Gastroenterol Hepatol 2003;18:1215-8.

Cite this article as: McKay MJ, Foster R. Pathobiology, irradiation dosimetric parameters and therapy of radiationinduced gastric damage: a narrative review. J Gastrointest Oncol 2021;12(6):3115-3122. doi: 10.21037/jgo-21-361
33. Kerin VV, Sinev IuV, Gavrilenko IaV, et al. Comparative results of the treatment of gastroduodenal ulcers with low-energy laser and hyperbaric oxygenation. Ter Arkh 1985;57:47-9.

34. Mossa M, Neri B, Scarozza P, et al. Super selective arterial embolization to treat radiation-induced hemorrhagic gastritis: a case report and review of the literature. Scand J Gastroenterol 2021;56:118-21.

35. Afifi ANAM, Powerski M, Jechorek D, et al. Radiationinduced damage in the upper gastrointestinal tract: clinical presentation, diagnostic tests and treatment options. Best Pract Res Clin Gastroenterol 2020;48-49:101711.

36. McKay MJ, Langlands AO. The American 'Patterns of Care' Study: a model for the assessment of the quality of patient care in radiation oncology. Australas Radiol 1990;34:306-11. 